\title{
POSSÍVEIS DIÁLOGOS ENTRE A EDUCAÇÃO FÍSICA ESCOLAR E O CONTEÚDO DAS LUTAS NA PERSPECTIVA DA CULTURA CORPORAL
}

\author{
Luiz Gustavo Bonatto Rufino, Universidade Estadual Paulista - UNESP, Rio Claro, São \\ Paulo-Brasil \\ Suraya Cristina Darido, Universidade Estadual Paulista - UNESP, Rio Claro, São Paulo - \\ Brasil
}

\begin{abstract}
RESUMO
O objetivo deste estudo foi analisar o contexto da temática das lutas na Educação Física escolar, considerando a concepção de cultura corporal e as dimensões dos conteúdos, estabelecendo assim possíveis "diálogos" entre estas práticas e a Educação Física. Para isso, foi realizada uma revisão de literatura abordando os seguintes tópicos: compreendendo as lutas, a temática das lutas na cultura corporal, ensinando as lutas na escola e as lutas nas três dimensões dos conteúdos. Concluímos que é preciso inserir as lutas na escola, levando-se em conta a questão das dimensões dos conteúdos, possibilitando que, além dos procedimentos, seja empregado também conceitos e atitudes em relação ao ensino destes conteúdos.
\end{abstract}

Palavras-Chave: Educação Física escolar; Lutas; Diálogos; Cultura corporal.

\section{POSSIBLE DIALOGUES BETWEEN SCHOOL PHYSICAL EDUCATION AND FIGHT'S CONTENDS IN BODY CULTURE PERSPECTIVE}

\begin{abstract}
The objective of this study was to analyze the context of fights in Physical Education classes, in school, considering the conception of body culture and the content dimension, establishing possible "dialogues" between the theme of fights and Physical Education. For this study we did a review of literature including the following topics: understanding the fights, the theme of fighting in body culture, teaching the fights at school and the fights in the tree dimensions of contents. We concluded that the fights must be inserted as one content at school, considering the dimensions of contents, allowing that beyond the procedures, the teachers could use the concepts and attitudes while they teach these contents.
\end{abstract}

Key-Words: School Physical Education; Fights; Dialogues; Body culture. 


\section{POSIBLE DIÁLOGOS ENTRE LA ESCUELA DE EDUCACIÓN FÍSICA Y LO CONTENIDO DE LAS LUCHAS IN LA PERSPECTIVA DE LA CULTURA DEL CUERPO}

\section{RESUMEN}

El objetivo de este estudio fue analizar el contexto de las luchas en las clases de Educación Física en la escuela, teniendo en cuenta la concepción de la cultura del cuerpo y la dimensión del contenido, establecer posibles "diálogos" entre el tema de las peleas y la Educación Física. Para este estudio se hizo una revisión de literatura, incluyendo los siguientes temas: La comprensión de las luchas, el tema de las luchas en la cultura del cuerpo, la enseñanza de la luchas en la escuela y las luchas en las dimensiones de los contenidos. Llegamos a la conclusión de que las luchas debe entrar en escuela, teniendo en cuenta la cuestión de las dimensiones de contenido, permitiendo, además de los procedimientos, también se emplea conceptos y actitudes hacia el aprendizaje de ese contenido.

Palabras-Clave: Escuela de Educación Física; Luchas; Diálogos; Cultura del cuerpo. 
Não é no silêncio que os homens se fazem, mas na palavra, no trabalho, na ação-reflexão"

Paulo Freire ${ }^{1}$

\section{INTRODUÇÃO}

De acordo com os Parâmetros Curriculares Nacionais, os $\mathrm{PCNs}^{2}$, o diálogo é um dos principais instrumentos de uma democracia justa, permitindo espaço ao consenso e ao dissenso. Dialogar pede capacidade de ouvir o outro e de se fazer entender. Portanto, a democracia deve valorizar o diálogo como forma de esclarecer conflitos. ${ }^{2}$ Tamanha a importância dada ao diálogo que este é um dos blocos de conteúdos do tema transversal ética, juntamente com o respeito mútuo, a solidariedade e a justiça. Deve-se valorizar o diálogo visando o esclarecimento e a superação de conflitos. ${ }^{2}$

Ao optarmos por estabelecer “diálogos” entre a área da Educação Física e a temática das lutas, pretendemos apresentar algumas características sobre o ensino desses conteúdos. Para os $\mathrm{PCNs}^{2}$ não há nem reais descobertas, nem real aprendizagem se estas não forem fruto de rica comunicação entre indivíduos. Portanto, para que haja mudanças e transformações da práxis escolar desses conteúdos, é preciso, antes de tudo, dialogar, discutir e debater sobre eles, possibilitando que uma visão crítica seja criada em relação ao ensino das lutas na escola.

$\mathrm{Na}$ verdade, o conteúdo das lutas, de acordo com alguns autores da área, ainda é pouco explorado por grande parte dos professores de Educação Física escolar. As lutas são uma das mais elementares manifestações da cultura corporal, juntamente com as danças, os jogos, os esportes, as atividades rítmicas, as brincadeiras, dentre outros. São práticas corporais construídas ao longo da história por razões de sobrevivência e de vivências lúdicas.

Entretanto, há inúmeras divergências em relação ao que ensinar sobre lutas dentro da área da Educação Física escolar. Talvez este seja um dos fatores relacionados que limitam o seu tratamento nas aulas de Educação Física na escola. Devido à divergência existente na área sobre qual terminologia que deve ser aplicada (lutas, artes marciais ou modalidades 
esportivas de combate), optamos por caracterizar essa temática como lutas. Essa denominação corrobora com Rufino e Darido ${ }^{3: 406}$ que afirmam:

Mais relevante não é a discussão sobre qual terminologia está mais correta ou deve ser empregada em relação à outra e sim discutir sobre a inserção desses conteúdos, [lutas, artes marciais, modalidades esportivas de combate] que fazem parte da cultura corporal, nas aulas de Educação Física.

Segundo Carreiro ${ }^{4}$ dentre os conteúdos que podem ser apresentados na Educação Física escolar, as lutas são um dos que encontram maior resistência por parte dos professores, com argumentos como: falta de espaço, falta de material, falta de vestimentas adequadas e associação às questões de violência. $\mathrm{O}$ autor sugere ainda que o professor que não conhece o conteúdo das lutas apropriadamente, pode também aprender sobre ele em livros, revistas, internet e até mesmo com os próprios alunos.

Aprender com os alunos e atualizar-se é certamente uma prerrogativa indispensável para qualquer professor. Contudo, é comum ainda a existência de cursos de Educação Física que formem profissionais com nenhum conhecimento específico dos conteúdos das lutas.

Do mesmo modo, Del Vecchio e Franchini ${ }^{5}$ consideram que a dificuldade em tratar com os conteúdos das lutas na escola deve-se, em grande parte, à formação do profissional de Educação Física que, em muitos casos, frequenta uma graduação deficiente em relação à esses conteúdos, restringindo-se à apenas uma modalidade (como o judô ou a capoeira, por exemplo), ou mesmo nem havendo a aplicação desses conteúdos no ensino superior.

Até mesmo quanto aos professores universitários que ministram esses conteúdos há algumas considerações, comparados aos docentes de outras disciplinas. Para Del Vecchio e Franchini ${ }^{5}$ a maior parte dos docentes que ministram conteúdos de lutas nas universidades teve contato direto com estes conteúdos na qualidade de praticante.

Se, por um lado, essa característica ameniza o problema do domínio de conhecimentos específicos por parte de quem irá transmiti-los, por outro, essa não é uma prática comum Conexões: revista da Faculdade de Educação Física da UNICAMP, Campinas, v. 11, n. 1, p. 145-170, jan../mar. 2013.147 ISSN: 1983-9030 
em relação ao ensino de outras disciplinas como fisiologia do exercício, biomecânica e aprendizagem motora, por exemplo, que são disciplinas ministradas na maioria das vezes por docentes que as estudaram como tópico central em seus programas de pós- graduação. ${ }^{5}$

Essa característica dos docentes de lutas pode trazer um outro problema, no qual seja: o do direcionamento da disciplina para um único estilo ou modalidade de luta ${ }^{5}$. Desse modo, o ensino dos conteúdos da temática das lutas torna-se restrito àquelas pessoas que tiveram contato com esses conteúdos, ou seja, praticantes ou ex-praticantes, reiterando-se que, mesmo assim, a tendência é que essas pessoas ensinem apenas a modalidade na qual tiveram mais contato, utilizando como recurso principal unicamente as suas experiências enquanto ex-praticantes/atletas e não conhecimentos científicos inovadores que permitam compreender os aspectos pedagógicos do ensino das lutas na escola.

O professor que ensinará estes conteúdos no Ensino Superior é, portanto, de fundamental importância à disseminação desses conteúdos por parte dos profissionais que serão formados por ele, sobretudo aqueles que darão aulas nas escolas. Com relação aos professores de Educação Física escolar, de acordo com Carreiro, ${ }^{4}$ é esperado que eles sintam-se capacitados a apresentar mais uma forma de expressão da Cultura Corporal, que é a temática das lutas, não sendo necessário ter formação em nenhuma modalidade específica (ser faixa preta de alguma modalidade, por exemplo).

Portanto, não é necessário que o professor de Educação Física escolar tenha profundos conhecimentos das lutas para que elas possam ser tratadas na Educação Física escolar, contanto que o professor tenha uma formação que o possibilite ter contato com esses conteúdos, como os conceitos básicos, as formas de ensinar e assim por diante.

Além dos problemas em relação à formação profissional, há também outro agravante com relação ao ensino dos conteúdos das lutas. A escassez no número de produção científica na área é um fator muito importante a ser considerado também. Esta carência de produção científica foi analisada por Correia e Franchini. ${ }^{6}$ Os autores realizaram um estudo onde 
descreveram a questão da produção acadêmica em lutas, artes marciais e modalidades de combate no Brasil.

Para isso, eles analisaram 11 periódicos nacionais (a escolha dos periódicos baseou-se no questionamento sobre quais periódicos eram utilizados para pesquisas nessa área à 17 profissionais/estudantes envolvidos com as lutas) no período de 1998 até 2008 (optou-se pelo ano de 1998 pois foi neste ano que a profissão de Educação Física foi regulamenta por lei, a lei número 9696 de primeiro de setembro de 1998, e, conjuntamente com isso, foi criado o Conselho Federal de Educação Física, o CONFEF). ${ }^{6}$

Os resultados indicam que do total de 2561 trabalhos publicados nestes periódicos ao longo desse tempo, apenas $75(2,93 \%)$ abordavam a temática das lutas, artes marciais e modalidades esportivas de combate em seu título, resumo ou nas palavras chaves. ${ }^{6}$

Em relação às áreas de estudo, a pesquisa baseou-se nas proposições de $\operatorname{Tani}^{7}$ que dividiu a estrutura acadêmica da Cinesiologia, Educação Física e Esporte em: Biodinâmica do Movimento Humano, Comportamento Motor Humano e Estudos Sócio-Culturais do Movimento Humano, áreas consideradas de caráter básico para este autor, e a área de Pedagogia do Movimento Humano e Adaptação do Movimento Humano (para a Educação Física) e o Treinamento Esportivo e a Administração Esportiva (para o Esporte), todas estas áreas consideradas de caráter aplicado. ${ }^{7}$

Desta forma, constatou-se o predomínio dos estudos conduzidos na área de Biodinâmica, tendo $40 \%$ do total de estudos da área, seguidos pelos Estudos Sócio-Culturais do Movimento Humano, com 32\% e Comportamento Motor com $8 \%$. Nas áreas de caráter mais aplicado, a Pedagogia do Movimento Humano teve 10,7\%, o Treinamento Esportivo teve $8 \%$, a Administração Esportiva teve 1,3\% e a Adaptação do Movimento Humano não teve nenhum estudo produzido. ${ }^{6}$

Conexões: revista da Faculdade de Educação Física da UNICAMP, Campinas, v. 11, n. 1, p. 145-170, jan../mar. 2013.149 ISSN: 1983-9030 
Estes resultados apontam para um baixo número de artigos voltados às lutas/ artes marciais/modalidades esportivas de combate e, dentre as modalidades mais pesquisadas estão o judô e a capoeira, duas modalidades bastante tradicionais no Brasil. ${ }^{6}$

Ainda para Correia e Franchini $^{6}$ a compreensão da multidimensionalidade destas manifestações corporais, implica na mobilização de saberes das mais diversas áreas. Portanto, é necessário que haja mais pesquisas nestas áreas, principalmente nas áreas com menor número de produção, como é o caso da área de Pedagogia do Movimento Humano e que estas pesquisas tenham procedimentos metodológicos especializados e que possam chegar a uma parcela maior de pessoas que estão atuando, ou seja, intervindo na prática da profissão. $^{6}$

Além da questão da formação profissional e da carência de produção científica na área, há ainda outro agravante, associado com os outros dois fatores: o ensino das lutas é pautado normalmente por questões ligadas a tradição oral e apartadas de questões científicas.

Permeados por inúmeros questionamentos e dispostos a solucionar alguns "conflitos" através de "diálogos" sobre essa temática, poderíamos nos indagar: afinal, é possível ensinar os conteúdos da temática das lutas nas aulas de Educação Física? O que poderíamos ensinar desses conteúdos na Educação Física escolar? Qual é a atual visão da Educação Física sobre esses conteúdos?

Sendo assim, o objetivo desse texto foi contextualizar o panorama atual das lutas na Educação Física escolar por meio de uma revisão de literatura sobre estudos que conceituem estas manifestações como representações da cultura corporal, analisando as possibilidades de implementações destes conteúdos nas aulas de Educação Física escolar, estabelecendo, desta maneira, "diálogos" entre o conteúdo das lutas e a área da Educação Física na escola. 


\section{COMPREENDENDO AS LUTAS}

A compreensão das lutas em sua pluralidade de significados não é uma tarefa fácil e requer que sejam considerados inúmeros fatores. Primeiramente, é preciso levar em conta que, em se tratando desses conteúdos, não é possível desmistificá-los e racionalizados, devido ao universo simbólico de representações e idéias que fazem parte dessa temática. Assim, até mesmo definir o que são lutas torna-se arriscado, considerando-se que ao definirmos, limitamos a nossa compreensão.

O dicionário Luft, ${ }^{8: 431}$ por exemplo, define o ato de lutar (do latim luctari) como: "combater/ pelejar, brigar/ disputar, competir/ trabalhar arduamente, esforçar-se, empenhar-se". Já o substantivo luta é definido como "ação de lutar/qualquer combate corpo a corpo/guerra, peleja/antagonismo/esforço, empenho."

Já para Iedwab e Standefer ${ }^{9}$ a luta também é patriotismo, religião, filosofia e, sobretudo, o modo de ser de um indivíduo. Os autores afirmam também que o tema central das lutas é a resolução dos conflitos que fazem parte da nossa vida.

Há dentro do contexto das lutas marciais, muita tradição, muito misticismo, muitas histórias envolvidas. Há relatos (embora não comprovados) de feitos sobre humanos, histórias de façanhas inacreditáveis, lutadores que foram verdadeiros heróis, e assim por diante. Até mesmo em alguns filmes sobre lutas observa-se, por diversas vezes, lutadores capazes de realizar feitos incríveis como derrotar sozinhos uma quantidade muito grande de oponentes, de uma só vez.

Por outro lado, nos últimos anos tem aumentado o número de artigos científicos, livros, dissertações, teses e trabalhos de conclusão de curso, embora ainda seja muito aquém do que poderia e deveria ser. Estes estudos possibilitam a racionalização de determinadas características das lutas, sobretudo fora do meio escolar, nas questões que tangem o treinamento e a preparação de atletas de lutas, a fisiologia das modalidades de lutas, o comportamento motor dos praticantes, dentre outros estudos. 
Desse modo, podemos destacar um conflito existente entre os conhecimentos oriundos da tradição das lutas com os estudos científicos realizados sobre essas práticas. Exemplificando: se outrora alguns professores/mestres de lutas exigiam treinamentos árduos e que duravam horas e até dias (fato evidenciado em alguns filmes sobre essa temática, por exemplo), atualmente questões relacionadas aos princípios do treinamento esportivo foram acrescentadas, desmistificando as antigas formas de treinar. Se um lutador de kung fu precisava ficar diversas horas realizando determinadas posições, hoje sabe-se que ele deve periodizar o seu treinamento, por exemplo.

Breda et al. ${ }^{10}$ constata que durante séculos as lutas foram ensinadas de forma rústica e disciplinadora e sofreram poucas mudanças dentro dos processos de ensino-aprendizagem. Os autores acreditam que a ciência e a pedagogia têm contribuído muito para o desenvolvimento do esporte, aproximando-o das lutas, buscando enriquecer as aulas de lutas com a inserção dos conhecimentos da Educação Física, assim como enriquecer as aulas de Educação Física com os conhecimentos das lutas. ${ }^{10}$

Podemos considerar que a racionalização provocada pelos estudos científicos eliminou algumas características das tradições das lutas, como a menor ênfase à alguns elementos como a saudação, a meditação, as técnicas de cunho mais holístico, dentre outras. Embora o âmbito escolar não permeie essas divergências, o ensino das lutas na escola não pode desconsiderá-las. Tanto as questões da tradição quanto da racionalização podem trazer benefícios ao ensino das lutas, dependendo da forma como forem considerados, estudados e tratados pelo professor.

É preciso considerar que a perspectiva sobre as lutas mudou com o passar do tempo e novas formas de lutar foram surgindo enquanto que outras modalidades foram extintas. Algumas modalidades atingiram o patamar de esportes olímpicos, como o judô, o taekwondo, o boxe amador, a esgrima e wrestling (luta olímpica). Atualmente, com os avanços da área do treinamento esportivo, como os princípios do treinamento e sua periodização, por exemplo, ampliaram-se as possibilidades de aprendizagem e rendimento nas modalidades. 
Para Betti ${ }^{11: 186}$ o método científico representa um importante caminho de legitimação da práxis do profissional de Educação Física porque permite problematizar afirmações genéricas como, por exemplo: "atividade física é boa para a saúde”, ou "o judô é bom para descarregar a agressividade”. Ou seja, não é possível excluir as inúmeras colaborações que a ciência e a racionalização podem trazer para a área das lutas.

Contudo, não se pode também restringir e racionalizar demais a concepção das lutas a ponto de não considerar a sua dimensão cultural e simbólica. As lutas possuem significados plurais e diversos, não sendo possível compreendê-las única e exclusivamente através da racionalização do conhecimento.

Betti $^{12}$ (1994), por exemplo, afirma que o ser humano realiza constantemente atividades simbólicas para poder dar valor e orientar suas ações e as lutas são, claramente, atividades envoltas em um universo simbólico plural e abrangente, variando de acordo com a visão que cada sociedade emprega sobre cada modalidade existente. $\mathrm{O}$ autor considera que todas as noções usadas para caracterizar e explicar o comportamento humano são consequência ou derivam de universos simbólicos, não podendo ser reduzidas a impulsos biológicos, instintos psicanalíticos ou reforço de satisfação.

Portanto, a compreensão das lutas enquanto um fenômeno polissêmico e abrangente só é possível se considerarmos os diversos aspectos que os relacionam como as questões tradicionais e científicas relacionadas à estas práticas corporais.

Há um grande número de lutas, cada uma com sua própria história e embasada em inúmeros significados diferentes. Desde o passado, cada sociedade compreendeu o fenômeno das lutas de um modo diferente, promovendo assim uma infinidade de práticas, algumas bem diferentes entre si, enquanto outras apresentam diversas similaridades.

Porém, é preciso considerar também que muito do que se afirma sobre as lutas pode não ser verdadeiro. Correia ${ }^{13}$ considera que do ponto de vista do senso comum, afirmações ISSN: 1983-9030 
como as de que as lutas são milenares, provenientes do oriente, possuem filosofia, geram saúde, disciplinam as pessoas, pregam uma cultura de paz, etc. são constituídas de “pretensões generalizantes” porque não correspondem à práxis social.

Em relação à afirmação que todas as lutas são provenientes do oriente, esta também pode ser uma afirmação questionada já que nem todas vieram do oriente como, por exemplo, o Sambo que é proveniente da Rússia, o Huka-Huka proveniente dos índios brasileiros e o Krav Maga oriundo de Israel.

Quanto à perspectiva da saúde, destaca-se, por exemplo, que o treinamento para competição em modalidades de lutas pode não gerar saúde e muito pelo contrário, provocar uma série de lesões, como afirmam Ide e Padilha ${ }^{14}$ ao constatarem que o jiu jitsu desportivo, por exemplo, é uma modalidade que pode ser considerada como altamente lesiva aos seus praticantes, acarretando problemas de luxações em algumas articulações como os ombros, além de lesões nas vértebras cervicais e lesões causadas pela asfixia dos estrangulamentos. Afirmar também que as lutas promovem uma cultura de paz é desconsiderar os aspectos históricos que relacionam as lutas com as guerras, conflitos e batalhas. $^{13}$

Correia $^{13}$ aponta que as lutas foram criadas para a guerra e não para o âmbito escolar. Poderíamos pressupor que, da mesma forma que as lutas não foram criadas para a escola, outras modalidades como o futebol, por exemplo, prática bastante empregada nas aulas de Educação Física escolar, também não foi criada visando a escola.

Portanto, para que as práticas de lutas sejam aplicadas nas aulas de Educação Física escolar, deve haver modificações ou uma transformação didático-pedagógica, como denomina Kunz. ${ }^{15}$ Dessa forma, Correia ${ }^{13}$ considera que ainda é necessário um longo processo de apropriação relacionado às lutas por parte dos profissionais de Educação Física, propiciando um aproximação acadêmica e profissional no que se relaciona à essas temáticas.

Para este autor:

Conexões: revista da Faculdade de Educação Física da UNICAMP, Campinas, v. 11, n. 1, p. 145-170, jan../mar. 2013.154 ISSN: 1983-9030 
Demandamos na atualidade por elementos teóricos e práticos mais consistentes e coerentes para uma imperiosa transformação/transposição didática [...]. Assim, talvez possamos diminuir nossa ignorância [...] sobre essas manifestações [lutas, artes marciais, modalidades esportivas de combate] e dar um tratamento mais responsável e menos demagógico/caricato para essas importantes objetivações culturais que compõem o patrimônio universal expresso pela cultura e, sobretudo, explorá-las como elementos indispensáveis ao desenvolvimento humano. ${ }^{13: 30}$

\section{A TEMÁTICA DAS LUTAS NA CULTURA CORPORAL}

As lutas, as danças, as atividades rítmicas, os esportes, os jogos, as atividades circenses, as atividades de aventura, dentre outras, são manifestações inseridas na esfera da Cultura Corporal, fazendo parte do modo de ser das pessoas e das sociedades, de diferentes formas, ao longo da história. É preciso permitir ao aluno o contato e vivências significativas com esses conteúdos, possibilitando-os articular reflexões críticas sobre estas práticas.

Darido e Souza Júnior ${ }^{16}$ destacam que a área da Educação Física escolar ultrapassa a idéia de estar voltada apenas para o ensino do gesto motor correto. Muito mais do que isso, cabe ao professor de Educação Física problematizar, interpretar, relacionar, analisar com seus alunos as amplas manifestações dessa Cultura Corporal, de tal forma que estes compreendam os sentidos e significados impregnados nas práticas corporais.

Ao longo dos anos, a concepção de Educação Física dentro do âmbito escolar foi se modificando. Para Soares, ${ }^{17}$ por exemplo, a Educação Física na escola é um espaço de aprendizagem e, portanto, de ensino. Mas ensinar o quê?

Soares ${ }^{17}$ afirma que historicamente a Educação Física ocidental moderna tem ensinado o jogo, a ginástica, as lutas, a dança, os esportes. Estes são conteúdos clássicos que permaneceram através do tempo transformando inúmeros de seus aspectos, para se afirmar como elementos da cultura, como linguagem singular do homem no tempo. ${ }^{17}$ 
Na clássica obra da área da Educação Física intitulada como Metodologia do Ensino da Educação Física, a temática das lutas e da capoeira (colocada de forma separada) também aparece. De acordo com Soares et al. ${ }^{18: 38}$

[...] a perspectiva sobre a cultura corporal [...] busca desenvolver uma reflexão pedagógica sobre o acervo de formas de representação do mundo que o homem tem produzido no decorrer da história, exteriorizadas pela expressão corporal: jogos, danças, lutas, exercícios ginásticos, esporte, malabarismo, contorcionismo, mímica e outros, que podem ser identificados como formas de representação simbólica de realidades vividas pelo homem, historicamente criadas e culturalmente desenvolvidas. (grifo nosso).

Há também a visão apresentada nos Parâmetros Curriculares Nacionais, os PCNs. ${ }^{19}$ Para os PCNs da Educação Física, esse componente curricular pode ser entendido como uma área que trata de um tipo de conhecimento, denominado de Cultura Corporal de movimento e que tem como temas o jogo, a ginástica, o esporte, as lutas, a dança, a capoeira e outras temáticas. ${ }^{19: 26}$ (grifo nosso).

Os PCNs ${ }^{19}$ afirmam ainda que as lutas são disputas em que o(s) oponente(s) deve(m) ser subjugado(s), com técnicas e estratégias de desequilíbrio, contusão, imobilização ou exclusão de um determinado espaço na combinação de ações de ataque e defesa.

Deve-se ressaltar que a definição dos $\mathrm{PCNs}^{19}$ inclui as lutas apenas nas questões que tangem as vivências práticas dessas modalidades como o equilíbrio ou desequilíbrio, técnicas de contusão ou exclusão de espaços, dentre outras, não mencionando, assim, outras formas de se abordar as lutas na escola como, por exemplo, incluir na definição questões como: o que são lutas ou questões relacionadas à história das modalidades, condutas dos praticantes, dentre outras possibilidades.

A Proposta Curricular do Estado de São Paulo para a área da Educação Física ${ }^{20}$ também aborda a temática das lutas, compreendendo-a com parte inerente da Cultura Corporal. Nela, é proposto que a Educação Física trate da cultura relacionada aos aspectos corporais, que se expressam de diversas formas, dentre as quais os jogos, a ginástica, as danças e atividades rítmicas, as lutas e os esportes ${ }^{20}$. (grifo nosso).

Conexões: revista da Faculdade de Educação Física da UNICAMP, Campinas, v. 11, n. 1, p. 145-170, jan../mar. 2013.156 ISSN: 1983-9030 
Embora afirme que não pretende restringir e sim diversificar os conteúdos, a proposta do Estado de São Paulo ${ }^{20}$ propõe que se trabalhe com a temática das lutas de forma genérica a partir apenas do quarto semestre do sétimo ano (antiga sexta série).

Há ainda a proposição de algumas modalidades como o judô, o caratê, o taekwondo e o boxe para o oitavo ano (antiga sétima série) além da proposição do conteúdo da capoeira para o nono ano (antiga oitava série). Já no Ensino Médio, a temática das lutas aparece apenas no primeiro semestre do terceiro ano, sendo enfatizada também no terceiro semestre desse mesmo ano. ${ }^{20}$

O Estado do Rio Grande do Sul também elaborou uma proposta curricular de apoio ao professor da rede estadual de ensino daquele estado. Na proposta relacionada à área da Educação Física, conteúdos sobre a temática das lutas também são abordados. As práticas esportivas, as ginásticas, as lutas, as atividades lúdicas, as práticas corporais expressivas, entre outras, se firmaram ao longo dos anos como objetos de estudo próprios da Educação Física. ${ }^{21: 114}$ (grifo nosso).

Quanto ao conteúdo das lutas, a proposta os classifica como pertencentes às práticas corporais sistematizadas. Dividem-se os saberes das lutas em dois: os saberes corporais que compreendem o saber praticar e o conhecer e os saberes conceituais, que compreendem os saberes técnicos e críticos. ${ }^{21}$

A proposta considera que os conteúdos abordados pelos professores de Educação Física na escola devem ser os mais amplos possíveis, tratando de diversas temáticas referentes à Cultura Corporal, não objetivando que os alunos tornem-se praticantes ou profundos conhecedores de uma ou outra prática corporal, mas sim que eles possam conhecer, vivenciar e discutir sobre o mais variado número de práticas referentes à Cultura Corporal. $^{21}$ 
Exemplificando, podemos considerar que uma determinada luta pode ser escolhida pelo professor como objeto de estudo de uma das unidades didáticas que tratam desses conteúdos. Tal escolha implicará a proposição de um fazer corporal em aula que leve os alunos a conhecerem tal prática, mas sem a pretensão de investir em um nível de apropriação que lhes permita praticar, fora da escola, a arte marcial estudada ${ }^{21}$. Entretanto, a temática das lutas aparece somente como componentes das sétimas e oitavas séries, (denominadas atualmente de oitavo e nono ano) durante apenas $8 \%$ do tempo relativo ao ensino dos conteúdos da Educação Física destes anos, com opções como o judô, o caratê, a capoeira e o taekwondo.

Finalmente, há a visão de Betti $^{22}$ que também destaca a temática das lutas em sua conceituação sobre a Educação Física na escola. Para este autor a Educação Física na escola é:

uma disciplina que tem por finalidade propiciar aos alunos a apropriação crítica da cultura corporal de movimento, visando formar o cidadão que possa usufruir, compartilhar, produzir e transformar as formas culturais do exercício da motricidade humana: jogo, esporte, ginásticas e práticas de aptidão física, dança e atividades rítmicas/ expressivas, lutas/ artes marciais, práticas alternativas. ${ }^{22: 64}$ (grifo nosso).

É interessante observar que em todas as propostas analisadas, a temática das lutas aparece de forma autônoma em relação ao conteúdo dos esportes, embora as lutas mais difundidas e praticadas em nossa sociedade e que aparecem na mídia, são as formas esportivas de modalidades de combate.

Talvez, o fato do conteúdo das lutas aparecerem de forma separada aos conteúdos dos esportes nas definições de Cultura Corporal apresentadas, seja uma forma de garantir a aplicação desses conteúdos na escola, mesmo que muitas lutas sejam também modalidades esportivas. Essa pode ser uma forma de permitir que os alunos se apropriem destes conteúdos nas aulas de Educação Física, além dos outros conteúdos referentes à Cultura Corporal. 
Dentre todas as propostas analisadas anteriormente ${ }^{4,17-22}$ fica evidente a inserção da temática das lutas como um importante conteúdo a ser ensinado nas aulas de Educação Física na escola, como uma das práticas que compõem o universo da Cultura Corporal.

Todavia, há ainda muitas incertezas sobre quais são as práticas relacionadas às lutas que devem ser efetivamente selecionadas para as aulas de Educação Física na escola e quando isso deve ocorrer nos espaços e tempos escolares. Sabe-se que as lutas são importantes, porém não há estudos que indiquem quando ensiná-las e, principalmente, o que ensinar das lutas ao longo do processo de escolarização.

Este fato é exemplificado com a inserção da temática das lutas em séries espaçadas, sem uma sequência lógica de ensino desses conteúdos. Algumas propostas inserem as lutas em séries e semestres sem uma clara explicação para isso, como a proposta do Estado do Rio Grande do $\mathrm{Sul}^{21}$ que considera as lutas como conteúdos apenas das sétimas e oitavas séries (atuais oitavo e nono ano).

Para facilitar a compreensão a respeito da falta de critérios com relação à escolha das modalidades por parte de alguns referenciais de proposição do ensino destes conteúdos, elaboramos um quadro que aborda quais modalidades de lutas são abordadas por algumas propostas de inserção das lutas na escola.

Quadro 1 - Apresenta quais modalidades de lutas são incluídas nas proposições referentes a alguns autores

\begin{tabular}{lcccccc}
\hline \multicolumn{1}{c}{ Autores } & Judô & Caratê & Capoeira & Boxe & Taekwondo & Esgrima \\
\hline Soares et al. $^{18}$ & & & $\checkmark$ & & \\
PCNs $^{19}$ & $\checkmark$ & $\checkmark$ & $\checkmark$ & $\checkmark$ & \\
São Paulo $^{20}$ & $\checkmark$ & $\checkmark$ & $\checkmark$ & $\checkmark$ & & $\checkmark$ \\
Rio Grande $_{\text {do Sul }}{ }^{21}$ & $\checkmark$ & $\checkmark$ & $\checkmark$ & & $\checkmark$ & \\
\hline
\end{tabular}

Conexões: revista da Faculdade de Educação Física da UNICAMP, Campinas, v. 11, n. 1, p. 145-170, jan../mar. 2013.159 ISSN: 1983-9030 
O Quadro 1 demonstra que apenas algumas modalidades de lutas foram adotadas, dentro de um universo muito mais amplo, nos possibilitando realizar alguns questionamentos. Entre tantas modalidades de lutas existentes, quais são aquelas que devem ser incluídas nas aulas de Educação Física escolar? Mais importante ainda seria nos perguntarmos: quais devem ser os critérios utilizados para a inclusão ou exclusão de modalidades de lutas na escola? Por fim, poderíamos questionar: o que ensinar de cada uma dessas modalidades inseridas nas aulas de Educação Física escolar?

Evidentemente que as lutas são mais um conteúdo, dentro do universo amplo e plural da Cultura Corporal. No entanto, um número maior de estudos e trabalhos deve ser conduzido de modo que seja considerado o universo da escola, as características dos alunos, a relevância social dos conteúdos, além de outras características.

\section{ENSINANDO AS LUTAS NA ESCOLA}

Antes de qualquer coisa devemos nos perguntar: é possível ensinar as lutas na escola? De acordo com as propostas analisadas e a opinião dos autores apresentados sim, é possível. Então, por que na prática o ensino dos conteúdos das lutas é algo tão pouco difundido e por que muitos professores não ensinam estes conteúdos em suas aulas?

Há certamente um conjunto de fatores intrinsecamente relacionados, num continuum que vai desde a formação profissional deficiente em relação a esses conteúdos, até o preconceito que ainda existe em relação a determinadas modalidades, passando pela falta de infra-estrutura das escolas, o apoio da direção e até as expectativas dos alunos e da comunidade em geral sobre qual é o papel da Educação Física na escola.

Porém, isso não significa que essa situação deva ser mantida. É direito dos alunos se apropriarem desses conteúdos, ao longo dos anos de educação formal dentro da escola e é dever do professor ensinar esses conteúdos, não pautados em apenas uma modalidade. Mais ainda, é dever da escola, através de seu projeto político pedagógico inserir esses conteúdos nas aulas de Educação Física. A prerrogativa que se abre não é mais se é possível ou não ensinar esses conteúdos, e sim o que ensinar desses conteúdos. 
Primeiramente, deve-se ter claro que a função da escola não é formar atletas, muito menos lutadores e/ou competidores de uma ou outra modalidade esportiva de combate. Deve-se prezar, a princípio, pela formação do cidadão que irá apropriar-se da Cultura Corporal em suas diferentes formas de manifestação (sendo as lutas apenas uma delas). Visa-se, com isso, a formação de pessoas éticas e autônomas. ${ }^{19}$

Portanto, a tarefa da escola vai além da simples apropriação ou execução de golpes, movimentos, gestos técnicos, enfim, os procedimentos estabelecidos. Sendo assim, ensinar as lutas é muito mais do que ensinar os alunos a submeterem seus companheiros por meio de golpes ou movimentos de oposição; ensinar as lutas transcende os movimentos e gestos. Ensinar as lutas é ampliar a visão sobre elas, possibilitando que sejam adquiridas novas visões e novos olhares a respeito dessa temática. Isso só é possível através da ampliação dos conteúdos.

Como exemplo da inserção destes conteúdos na escola há a proposição de Darido e Souza Júnior ${ }^{16}$ que incluem esta temática como um possível conteúdo a ser ensinado na escola. Os autores ilustram algumas vivências, jogos e brincadeiras sobre estas práticas, permitindo que os professores de Educação Física escolar (mesmo aqueles que possuem menos contato com esta temática) possam trabalhar com as lutas através de diferentes formas e vivências.

Os autores propõem ainda que sejam tratados outras questões além das vivências de jogos, brincadeiras e outras dinâmicas, como, por exemplo: conceituação de algumas modalidades de lutas, a história de determinadas práticas, a questão da diferença entre lutar e brigar, algumas curiosidades sobre as lutas, dentre outras questões. ${ }^{16}$

\section{AS LUTAS NAS TRÊS DIMENSÕES DOS CONTEÚDOS}

Proposto por Coll, ${ }^{23}$ as três dimensões dos conteúdos é uma forma de ampliar a visão sobre as possibilidades a serem ensinadas na escola, expandindo assim o papel da educação, indo além de uma ou outra dimensão. 
Coll $^{23}$ classifica os conteúdos em três dimensões, cada uma respondendo à um questionamento, sendo eles:

- O que se deve saber? (Dimensão conceitual);

- O que se deve fazer? (Dimensão procedimental);

- Como se deve ser? (Dimensão atitudinal).

Dessa forma, a dimensão conceitual do ensino das lutas poderia abranger os aspectos dos conceitos sobre as diferentes modalidades, suas regras, estudos e análises sobre as corretas formas de se realizar determinados movimentos, fatos históricos sobre as diferentes modalidades, dentre outras possibilidades.

Como exemplos da aplicação da dimensão conceitual no ensino das lutas na escola poderíamos considerar questões como: diversos tipos de modalidades existentes, formas de classificação das modalidades, diferentes origens para as diferentes práticas, as regras de determinadas modalidades, análise das modalidades consideradas olímpicas, pesquisas de modalidades desconhecidas, conceitos biomecânicos e fisiológicos envolvidos como a melhor forma de aplicação de alguns golpes e formas de se treinar estas modalidades, dentre inúmeras outras possibilidades.

Já a dimensão procedimental do ensino das lutas corresponde ao saber fazer, ou seja, os procedimentos, os movimentos e gestos técnicos realizados nas modalidades, tanto individuais quanto em dupla e/ou grupo, correspondendo assim a tudo que relaciona-se ao saber fazer. Exemplos de aplicação da dimensão procedimental nas aulas de Educação Física abrangendo o tema das lutas também são muito variados como: vivências relativas a questões de oposição, ganho ou perda de espaço, quedas, atividades individuais como simulação de técnicas de chutes e socos, atividades em dupla, em grupos (como o tradicional cabo de guerra), realização de brincadeiras e jogos pré-desportivos relacionados à temática das lutas, dentre outras muitas possibilidades.

Por fim, a dimensão atitudinal compreende as atitudes e valores que devem ser ensinados em relação às lutas, como as condutas éticas, valores e princípios orientadores das práticas 
como o respeito mútuo, a solidariedade, dentre outros. Há também vários exemplos de aplicação da dimensão atitudinal nas aulas de Educação Física na escola sobre a prática das lutas como: respeito ao companheiro, diferenciação entre luta e briga, discussão de termos como "porrada", "massacre" e "guerra”, discussões a respeito da hierarquia imposta à algumas modalidades, questões relativa ao respeito aos limites do próprio corpo no que tange alguns golpes e posições de algumas práticas, a ética necessária para não se utilizar os conhecimentos aprendidos com outras pessoas em outros ambientes, dentre outras possibilidades.

Deve-se destacar que, embora as dimensões sejam divididas em três, na prática do processo de ensino-aprendizagem elas devem estar atreladas uma a outra, não sendo possível aplicar o ensino das lutas em cada dimensão de forma separada e/ou isolada e sim interagindo-as entre si, promovendo assim a ampliação da visão, facilitando a aprendizagem dessas práticas.

Embora muitos caracterizem as lutas como práticas holísticas que promovem o respeito, a disciplina, dentre outros valores, é preciso destacar que essas modalidades, assim como os demais esportes, não são por si só provedoras desses valores, dependem de como o professor ensinará esses conteúdos.

Bracht $^{24: 64}$ traz uma importante contribuição a esse respeito ao afirmar que, se por um lado, o esporte pode promover a socialização, por outro, ele pode espelhar as condições de uma sociedade autoritária, aceitando as regras impostas onde o princípio de rendimento se impõe a todos os outros.

Bracht $^{24}$ afirma ainda que o esporte pode desenvolver idéias e valores que levem ao conformismo e ao respeito incondicional de regras, promovendo uma educação que leve ao acomodamento, uma educação a serviço da classe dominante. Porém, o autor considera que embora não seja possível mudar o sistema (capitalista) é possível realizar algumas mudanças dentro do sistema possibilitando que o esporte, sobretudo aquele praticado na escola, não seja voltado única e exclusivamente ao rendimento.

Conexões: revista da Faculdade de Educação Física da UNICAMP, Campinas, v. 11, n. 1, p. 145-170, jan../mar. 2013.163 ISSN: 1983-9030 
Para Bracht ${ }^{25}$ os professores de Educação Física devem entender que o que determinará o uso que o indivíduo fará do movimento não é determinado pela condição física, habilidade desportiva, flexibilidade, etc., e sim pelos valores e normas de comportamento introjetados, pela condição econômica e pela posição na estrutura de classes de nossa sociedade.

Nessa visão, podemos considerar que o esporte é uma construção histórico-social humana em constante transformação e fruto de múltiplas determinações. Em relação ao esporte na escola, podemos considerar que enquanto atividade escolar ele só tem sentido se integrado ao projeto pedagógico da escola ${ }^{25}$.

Portanto, as lutas, assim como todos os outros conteúdos da Educação Física escolar, dependem não só de como são tratados pelo professor, mas também de como estão estabelecidos no projeto político pedagógico da escola, sobretudo considerando se há a ampliação de significados sobre esta temática ou não.

Dessa forma, as dimensões dos conteúdos são uma forma de ampliar o conhecimento sobre os aspectos das lutas, não restringindo o ensino aos aspectos apenas procedimentais, o "saber fazer", mas indo além, transcendendo para os conhecimentos das outras dimensões, como as atitudes e os conceitos. Nas palavras de Freire: ${ }^{1: 45}$

O que importa, na formação docente, não é a repetição mecânica do gesto, este ou aquele, mas a compreensão do valor dos sentimentos, das emoções, do desejo, da insegurança a ser superada pela segurança, do medo que, ao ser 'educado', vai gerando a coragem.

É claro que para isso o professor deve ter uma formação acadêmica e continuada adequada para lidar com esses conteúdos, não necessitando que, para isso, eles sejam praticantes assíduos em modalidades de combate, e sim que eles possam ter conhecimentos das lutas nas três dimensões dos conteúdos e que saibam como transmitir esses conhecimentos para os alunos numa perspectiva formadora.

\section{CONSIDERAÇÕES FINAIS}

O professor só pode ensinar aquilo que ele conhece, que lhe é familiar, aquilo que ele tem domínio mas, sobretudo, ele só ensinará aquilo que for válido e verdadeiro a seus próprios 
olhos $^{26}$. Sem conhecer e compreender as lutas enquanto um fenômeno plural e abrangente, o seu ensino continuará sendo negado aos alunos, mesmo com a presença das lutas nas propostas curriculares dos estados e da posição dos autores analisados.

Continuar-se-á então com a mesma cadência (ou decadência) em torno das possibilidades do que se ensina/aprende nas aulas de Educação Física escolar em relação a esse tema (salvo algumas exceções), ou seja, continuará o não ensino desses conteúdos, ou então a limitação à apenas algumas modalidades, sem o aprofundamento sobre os diversos aspectos que o universo das lutas abrangem, seja em termos biológicos, em termos históricos, em termos de condutas éticas, dentre outros.

Ampliar a visão sobre esse tema é uma forma de ensinar as lutas de maneira melhor, mais qualificada, mais abrangente e visando ir além dos preceitos práticos, compreendendo, além da dimensão procedimental, as dimensões conceitual e atitudinal. Mais do que isso, deve-se compreender as lutas para ensinar mais do que as lutas em si. Breda et al. ${ }^{10}$ afirmam que os alunos tem o direito de aprender a lutar e aprender mais que lutar, aprender a ser.

De fato as lutas oferecem inúmeras possibilidades tanto de prática quanto de metáforas para a vida. Tanto é que o conceito de "luta" não é limitado única e exclusivamente à concepção esportiva, lutar vai além de ser apenas um esporte.

Estas "metáforas" com o termo do lutar nos permite abordar outras questões, indo além de considerar o lutar apenas como práticas corporais. Lutar é opor-se, é enfrentar, é resistir. Lutar é a arte da não aceitação, mesmo que para isso, muitas vezes seja necessário primeiro ceder, para depois vencer. Para Freire ${ }^{1}$ lutar é enfrentar, é opor resistência e isso faz parte da vida, indo muito além das práticas corporais em si.

Destacamos a frase de Rubem Alves, escrita no prefácio do livro de Marcellino ${ }^{27: 11}$ intitulado "Pedagogia da Animação":

Poesia é coisa fraca. E o mundo em que vivemos exige que sejamos fortes. Que pode a poesia contra a dureza da pá e da esquadria, contra a Conexões: revista da Faculdade de Educação Física da UNICAMP, Campinas, v. 11, n. 1, p. 145-170, jan../mar. 2013.165 ISSN: 1983-9030 
força do cimento e do dinheiro? Não sabem eles que é da beleza da poesia que nascem os guerreiros. Lutam melhor aqueles em cujos corpos moram os sonhos. Para se lutar não basta ter corpo e saber competentes: é preciso ter alma

Portanto, a luta é imprescindível ao homem. Aliás, Bertolt Brecht caracteriza as pessoas que lutam por toda a vida como "seres imprescindíveis". É claro que esta visão extrapola os conceitos estabelecidos sobre lutas, artes marciais e modalidades esportivas de combate, porém, como o intuito foi estabelecer possíveis diálogos, muitas vezes necessitamos ampliar a nossa visão para que os diálogos possam existir e, se há algo que o conceito do lutar nos possibilita, esse algo é a capacidade de acreditar que "é possível”. Acreditar que é possível mudar, que é possível não aceitar e que podemos enfrentar. Conforme afirmou Rubem Alves: "para se lutar não basta ter corpo e saber competentes: é preciso ter alma", ${ }^{27}$ pois a vida pode ser considerada como a dinâmica de uma luta, tornando-se impossível dissociar o lutar do viver.

Dessa forma, tratar os conteúdos das lutas nas aulas de Educação Física é necessário, como foi visto. Mas é necessário saber que lutas são estas e como serão ensinadas, quais modalidades e, certamente, o que e o porquê de serem ensinadas essas modalidades.

É preciso que as lutas, juntamente com os outros conteúdos da Cultura Corporal sejam aplicadas nas aulas de Educação Física na escola nas diversas séries, em diversos semestres, promovendo para os alunos, algo que eles ainda não têm em relação à essa temática, que é a vivência de diferentes modalidades, a apropriação crítica da cultura envolta nessas práticas e a ampliação dos conteúdos, promovidos pelas dimensões dos conteúdos.

Todavia, é fato que a Educação Física ainda não se apropriou adequadamente dos conteúdos relacionados às lutas considerando a questão do que ensinar sobre elas na escola. Em meio a embates sobre legitimação de aplicação profissional, falta de produção acadêmica e uma precária formação profissional, há o âmbito escolar, local que embora tenha encontrado algumas convergências em relação ao trato dos conteúdos da área da 
Educação Física, ainda está longe de ser um ambiente de avanços em relação à implementação de conteúdos como as lutas.

É preciso que o professor compreenda a importância da inserção das lutas na escola e entenda que os conteúdos são necessários, fazem parte da Cultura Corporal, são elementos dessa cultura e os alunos têm o direito de conhecê-los e vivenciá-los. Entretanto deve-se ressaltar que, se os alunos têm o direito de conhecer esses conteúdos, os professores têm o dever de ensiná-los, e para isso eles devem compreendê-los e transformá-los, para a melhor apropriação por parte dos alunos, numa troca que faça com que ambos, alunos e

professores cresçam, se transformem e aprendam, já que como Paulo Freire ${ }^{1: 23}$ afirmou: “quem ensina aprende ao ensinar e quem aprende ensina ao aprender".

\section{REFERÊNCIAS}

${ }^{1}$ FREIRE, P. Pedagogia da autonomia: saberes necessários à prática educativa. São Paulo: Paz e Terra, 1996.

${ }^{2}$ BRASIL. Ministério da Educação. Secretaria de Educação Fundamental. Parâmetros curriculares nacionais: apresentação dos temas transversais e ética. Brasília, 2000.

${ }^{3}$ RUFINO, L. G. B.; DARIDO, S. C. O jiu jitsu brasileiro nas três dimensões dos conteúdos nas aulas de educação física escolar. In: IV COLÓQUIO DE PESQUISA QUALITATIVA EM MOTRICIDADE HUMANA: AS LUTAS NO CONTEXTO DA MOTRICIDADE, 4.; III SIMPÓSIO SOBRE O ENSINO DE GRADUAÇÃO EM EDUCAÇÃO FÍSICA: 15 ANOS DO CURSO DE EDUCAÇÃO FÍSICA DA UFSCar; SHOTO WORKSHOP, 5., 2009, São Carlos. Anais... São Carlos: UFSCar, 2009. CD ROM.

${ }^{4}$ CARREIRO, E. A. Lutas. In: DARIDO, S. C.; RANGEL, I. C. A. Educação Física na escola: implicações para a prática pedagógica. Rio de Janeiro: Guanabara Koogan, 2005. 
${ }^{5}$ DEL VECCHIO, F. B.; FRANCHINI, E. Lutas, artes marciais e esportes de combate: possibilidades, experiências e abordagens no currículo da Educação Física. In: SOUZA NETO, S.; HUNGER, D. Formação profissional em Educação Física: estudos e pesquisas. Rio Claro: Biblioética, 2006.

${ }^{6}$ CORREIA, W. R.; FRANCHINI, E. Produção acadêmica em lutas, artes marciais e esportes de combate. Motriz, Rio Claro, v. 16, n. 1, p. 01-09, 2010.

${ }^{7}$ TANI, G. Cinesiologia, educação física e esporte: ordem emanente do caos na estrutura acadêmica. Motus Corporis, Rio de Janeiro, v. 3, n. 2, p. 9-49, 1996.

${ }^{8}$ LUFT, C. P. Minidicionário Luft da língua portuguesa. 20. ed. São Paulo: Ática, 2000.

${ }^{9}$ IEDWAB, C.; STANDEFER, R. Um caminho de paz: um guia das tradições das artes marciais para os jovens. São Paulo: Cultrix, 2001. 102 p.

${ }^{10}$ BREDA, M. et al. Pedagogia do esporte aplicada às lutas. São Paulo: Phorte, 2010.

${ }^{11}$ BETTI, M. Educação física como prática científica e prática pedagógica: reflexões à luz da filosofia da ciência. Revista Brasileira de Educação Física e Esporte, v.19, n. 3, p. 183-197, 2005.

${ }^{12}$ BETTI, M. Valores e finalidades na educação física escolar: uma concepção sistêmica. Revista Brasileira de Ciências do Esporte, Santa Maria, v. 16, n. 1, p. 14-21. 1994.

${ }^{13}$ CORREIA, W. R. Lutas e artes marciais na escola: questões insólitas. In: COLÓQUIO DE PESQUISA QUALITATIVA EM MOTRICIDADE HUMANA: AS LUTAS NO CONTEXTO DA MOTRICIDADE, 4.; SIMPÓSIO SOBRE O ENSINO DE GRADUAÇÃO EM EDUCAÇÃO FÍSICA: 15 ANOS DO CURSO DE EDUCAÇÃO FÍSICA DA UFSCAR, 3.; SHOTO WORKSHOP, 5., 2009, São Carlos. Anais... São Carlos: UFSCar, 2009. CD ROM.

Conexões: revista da Faculdade de Educação Física da UNICAMP, Campinas, v. 11, n. 1, p. 145-170, jan../mar. 2013.168 ISSN: 1983-9030 
${ }^{14}$ IDE, B. N.; PADILHA, D. A. Possíveis lesões decorrentes da aplicação das técnicas do jiu jitsu desportivo. Lecturas, Educación Física y Deportes: revista digital, Buenos Aires, ano 10, n. 83, 2005. Disponível em: 〈http://www.efdeportes.com/efd83/jiu.htm>. Acesso em: 15 fev. 2010.

${ }^{15}$ KUNZ, E. Transformação didático-pedagógica do esporte. Ijuí: Ed. da Unijuí, 1994.

${ }^{16}$ DARIDO, S. C; SOUZA JÚNIOR, O. Para ensinar Educação Física: possibilidades de intervenção na escola. Campinas: Papirus, 2007.

${ }^{17}$ SOARES, C. L. Educação Física escolar: conhecimento e especificidade. Revista Paulista de Educação Física, São Paulo, supl. 2, p. 6-12, 1996.

${ }^{18}$ SOARES, C. L. et al. Metodologia do ensino da Educação Física. São Paulo: Cortez, 1992.

${ }^{19}$ BRASIL. Ministério da Educação e do Desporto. Secretaria de Educação Fundamental. Parâmetros Curriculares Nacionais: Educação Física, $3^{\circ}$ e $4^{\circ}$ ciclos. Brasília, 1998. v.7b.

${ }^{20}$ SÃO PAUlO. Secretaria da Educação do Estado de São Paulo. Proposta Curricular do Estado de São Paulo: Educação Física, ensino fundamental, ciclo ii e ensino médio. São Paulo, 2008.

${ }^{21}$ RIO GRANDE DO SUL. Secretaria de Estado de Educação. Referenciais Curriculares do Estado do Rio Grande do Sul: linguagens, códigos e suas tecnologias. Porto Alegre, 2009. v.2.

${ }^{22}$ BETTI, M. Educação Física escolar: ensino e pesquisa ação. Ijuí: Ed. da Unijuí, 2009.

Conexões: revista da Faculdade de Educação Física da UNICAMP, Campinas, v. 11, n. 1, p. 145-170, jan../mar. 2013.169 ISSN: 1983-9030 
${ }^{23}$ COLL, C. Os conteúdos na reforma. Porto Alegre: Artmed. 2000.

${ }^{24}$ BRACHT, V. A criança que pratica esporte respeita as regras do jogo... capitalista. Revista Brasileira de Ciências do Esporte, Campinas, v. 7, n. 2, p. 62- 68, 1986.

${ }^{25}$ BRACHT, V. Esporte na escola e esporte de rendimento. Movimento, Porto Alegre, ano 7, n. 12, p. 14-24, 2000.

${ }^{26}$ FORQUIN, J. C. Escola e cultura: as bases sociais e epistemológicas do conhecimento escolar. Porto Alegre: Artes Médicas, 1993.

${ }^{27}$ MARCELlinO, N. C. Pedagogia da animação. Campinas: Papirus, 1989. 